\title{
Quality of life of patients with chronic kidney disease in two health facilities in Delta State, Nigeria
}

\author{
Ogheneovo C Aghoja ${ }^{1 *}$, Rita O Akonoghrere ${ }^{1}$, Valentine U Odili², Omasan \\ Ajagbe ${ }^{3}$ \\ ${ }^{1}$ Department of Clinical Pharmacy and Pharmacy Administration, Faculty of Pharmacy, Delta State University, Abraka, \\ ${ }^{2}$ Department of Clinical Pharmacy and Pharmacy Practice, University of Benin, Benin City, ${ }^{3}$ Safari Pharmacy, Warri, Nigeria \\ *For correspondence: Email: stmajella@yahoo.co.uk; Tel: +234-8028427771
}

\begin{abstract}
Purpose: To determine patients' quality of life $(Q \circ L)$, impact of socio-demographic characteristics as well as biochemical parameters on the quality of life of chronic kidney disease patients.

Methods: The study was a prospective, cross-sectional study carried out in the Renal Units of Central Hospital, Warri and Delta State University Teaching Hospital, Oghara, both in Nigeria. The quality of life of the patients was assessed using the generic core of Kidney Disease Quality of Life Short Form (KDQOL-SFTM) questionnaire. Data obtained were coded into the KDQOL--SF ${ }^{T M}$ scoring program (version 1.3), while descriptive and inferential analyses were done using SPSS

Results: Overall, the quality of life scores of patients with chronic kidney disease in both Physical and Mental Health components (PCS and MCS) was low. Respondents' PCS scores in Central Hospital Warri was $31.08 \pm 4.62$ while that for respondents in DELSUTH was $31.75 \pm 6.01,(p=0.39)$. Similarly, the MCS score for respondents in Central Hospital Warri was $37.73 \pm 3.37$ while it was $37.68 \pm 4.09$ for DELSUTH $(p=0.94)$. These scores were lower than the standard norm, which is 50 There was no relationship between socio-demographic characteristics and the quality of life of the respondents in both health facilities. Serum creatinine and potassium showed a negative association with quality of life PCS ( $p=.025$ and $p=.006 ; 2$-tailed), respectively.

Conclusion: In general, the QoL of patients with chronic kidney disease in the two surveyed settings was low. None of the socio-demographic characteristics had a significant relationship with the QoL of the respondents in both health centres. There was a negative association between PCS score and both creatinine and potassium.
\end{abstract}

Keywords: Quality of life (QoL), Patients, Chronic kidney disease, Creatinine, Potassium

This is an Open Access article that uses a fund-ing model which does not charge readers or their institutions for access and distributed under the terms of the Creative Commons Attribution License (http://creativecommons.org/licenses/by/4.0) and the Budapest Open Access Initiative (http://www.budapestopenaccessinitiative.org/read), which permit unrestricted use, distribution, and reproduction in any medium, provided the original work is properly credited.

Tropical Journal of Pharmaceutical Research is indexed by Science Citation Index (SciSearch), Scopus, International Pharmaceutical Abstract, Chemical Abstracts, Embase, Index Copernicus, EBSCO, African Index Medicus, JournalSeek, Journal Citation Reports/Science Edition, Directory of Open Access Journals (DOAJ), African Journal Online, Bioline International, Open-J-Gate and Pharmacy Abstracts

\section{INTRODUCTION}

An important health concern increasingly recognized globally is kidney disease. There is an increase in prevalence and incidence of kidney failure, poor treatment outcomes, and high cost of therapy [1,2]. Renal disease progression may be prevented or delayed by early detection and treatment [3]. Elimination of several drugs and their metabolites is through the renal system. Therefore, irrational drug use in 
patients with renal impairment $(\mathrm{RI})$ may have toxic effects [4-6].

Patients with chronic kidney disease (CKD) and patients on dialysis are closely monitored by nephrologists. However, the severity of the CKD was from minor to severe renal damage necessitating renal transplant or renal replacement therapy. Concomitant use of many drugs due to comorbidity makes management of these patients tasking. Patients with CKD have a better QoL than patients on dialysis, but poorer than the general population $[7,8]$. Quality of life of CKD patients are affected by certain factors such as anemia, comorbidities, age, depression and early treatment by nephrologist $[7,9,10]$. The quality of life of renal patients is a measure of the value of medical care received [11].

Availability of resources can limit management of these co-morbidities and thus can lead to further compromise in quality of life. Given the wellknown high rate of hospitalization and mortality in patients with CKD, evaluation of QoL is essential. $[12,13]$. Early intervention is important to slow disease progression and reduce the rate of hospitalization. A variety of additional factors should be considered in addressing the QoL of patients with CKD. Inaccessibility to health care, in general, is a significant problem. In geriatric patients or patients with a high level of comorbidity, the most appropriate treatment plan should be evaluated in each case, considering all the possible factors.

A survey suggested that patient outcome may be improved when care is provided by a multidisciplinary nephrology team [14]. While evaluation of QoL of CKD patients has been done in other countries, however, there is little or no information available in Nigeria. Study objectives were to determine patients' quality of life and impact of socio-demographic characteristics as well as biochemical parameters on the quality of life of patients with chronic kidney disease.

\section{METHODS}

\section{Study design}

The study was a prospective, cross-sectional study carried out in the Renal Units of Central Hospital, Warri and Delta State University Teaching Hospital, Oghara, both in Delta State, Nigeria. for a period of one year- June 2016 to May 2017 in Central hospital Warri, and April 2017 to March 2018 in DELSUTH, Oghara.

\section{Settings}

The study was carried out in Central Hospital Warri, a secondary health care institution with 252 beds, and Delta State University Teaching Hospital (DELSUTH), Oghara. Among other specialties, Central hospital Warri had a renal unit with two Consultant Nephrologists and five dialysis machines; with one of the dialysis machines dedicated to renal patients who are HIV positive and those who have hepatitis. The hospital has very high patient traffic compared to other secondary health institutions with an inpatient and out-patients' attendance rate of 10,574 and $1,083,079$ respectively per year.

Delta State University Teaching Hospital (DELSUTH), Oghara is a two hundred and twenty (220-bed) hospital with high patient traffic because it is the only teaching hospital in the State. The Nephrology Department has two Consultant Nephrologists, three Senior Registrars and seven Registrars. The department has eight dialysis machines with three of the dialysis machines dedicated to renal patients who are HIV positive and those who have hepatitis.

\section{Inclusion and exclusion criteria}

All adult patients diagnosed with chronic kidney disease and attending the renal clinics of the two health care facilities were included in the study, but those that were too ill to participate in the study were excluded.

\section{Sample size and sampling technique}

All the consenting patients that met the inclusion criteria were consecutively recruited during the period of the study.

\section{Ethical consideration}

Ethical approval was secured from the ethics committee of Delta State University Teaching Hospital (approval no. DELSUTH/HREC/2017/ 012/0236, dated 01/03/2017) and Central Hospital, Warri (approval no. CHW/ECC VOL 1/086, dated 05/04/2016) before the study commenced. Though the study was not invasive, the Helsinki declaration for study on human subjects was followed [15].

\section{Instrument and technique for data collection}

The generic core of Kidney Disease Quality of Life Short Form (KDQOL-SF ${ }^{\mathrm{TM}}$ ) questionnaire was used to collect the required information from the patient. The instrument comprised two 
sections, Section A, which is sociodemographic and Section $B$, which is the kidney disease quality of life questionnaire (SF-36). "The SF-36 instrument has 36 items. Only 35 of the items, representing eight scales and two summary measures, were utilized in this study. A final item, termed self-reported health transition, is answered by the client but is not included in the scoring process. The physical component summary and mental component summary are the two summaries. The physical component summary comprises scales of pain (2 items), physical functioning (10 items), general health perception (5 items) and role limitations caused by physical health problems (4 items). The four scales of mental component summary [MCS] were role limitations caused by emotional health problems (3 items), social functioning ( 2 items), emotional well-being (5 items) and energy/ fatigue (4 items)".

Cronbach's alpha coefficient of 0.923 was obtained for the 35 items. Disease-targeted component, which is the third component include "eleven scales that relate to the kidney disease. They are symptoms/problems, effects of kidney disease on daily life, burden of kidney disease, work status, cognitive function, and quality of social interaction, sexual function, sleep, social support, dialysis staff encouragement and patient satisfaction. These 11 subscales (items) make up the kidney disease component summary (KDCS)". The questionnaire was selfadministered, with assistance given to those who could not read.

\section{Data analysis}

The completed questionnaires were entered after coding into the KDQOL--SF ${ }^{\mathrm{TM}}$ scoring program (version 1.3) which is an Excel 97 spreadsheet that" analyzes and yields a score for each scaletwo summary measures and total SF-36. Each scale was scored 0 - 100 with a higher score indicating a better quality of life, and a mean score of 50 as the norm for all the scales. The mean scores of the two summary measures and the SF-36 are based on the average of the respective scale components.

Descriptive analysis, presenting variables in frequencies and percentages, and inferential analysis such as t-test and correlation were done using SPSS $(p<0.05)$.

\section{RESULTS}

The socio-demographic characteristics of our respondents are as presented in Table 1 . The mean age of the respondents was $51.25 \pm 16.61$ years. Majority of the respondents were female $97(53.3 \%)$, married 150 (82.4\%), were into one form of business or the other 69 (38.5\%), and neither took alcohol 154 (84.6\%) nor smoked $168(92.3 \%)$.

Table 1: Socio-demographics of respondents

\begin{tabular}{lll}
\hline Variable & & $\begin{array}{l}\text { Frequency } \\
(\mathbf{\%})\end{array}$ \\
\hline Center & Central Hospital, & $102(56)$ \\
& Warri & \\
Sex & DELSUTH & $80(44)$ \\
& Male & $85(46.7)$ \\
Marital status & Female & $97(53.3)$ \\
& Single & $30(16.5)$ \\
& Married & $150(82.4)$ \\
Occupation & Divorced & $2(1.1)$ \\
& Student & $16(8.9)$ \\
& Tailoring & $8(4.5)$ \\
& Civil Servant & $41(22.9)$ \\
& Trading (Business) & $69(38.5)$ \\
& Farming & $2(1.1)$ \\
& Contractor & $3(1.6)$ \\
Alcohol & Plumbing & $2(1.1)$ \\
Smoking & Pensioner & $41(22.9)$ \\
& Yes & $28(15.4)$ \\
& Yes & $14(7.7)$ \\
& Total & $\mathbf{1 8 2 ( 1 0 0 )}$ \\
\hline
\end{tabular}

Overall, the quality of life of patients with chronic kidney disease based on the PCS and MCS scores in the two surveyed settings was low. The mean total score PCS score for respondents in Central Hospital Warri was $31.08 \pm 4.62$ while that for respondents in DELSUTH was $31.75 \pm$ 6.01, $p=0.39$. Similarly, the MCS score for respondents from Central Hospital Warri was $37.73 \pm 3.37$ and $37.68 \pm 4.09$ for DELSUTH $p=$ 0.94 . However, the MCS score for both facilities were higher than the corresponding PCS score (Table 2).

None of the socio-demographic characteristics had a significant relationship with the quality of life of the respondents in both health facilities $p>$ 0.05 (Table 3 and Table 4). The mean value for urea was $194.05 \pm 99.14$ while that for creatinine was $12.55 \pm 8.93$. Similarly, the mean value for potassium and sodium was $5.11 \pm 1.27$ and $138.89 \pm 10.97$ respectively. There was a negative association between physical health composite and creatinine as well as potassium ( $p$ $<0.05$ ) [Table 5].

\section{DISCUSSION}

This study revealed that the overall QoL of patients with CKD was low. Generally, patients with CKD had a low mean score in both physical and mental health components. This low mean score could be attributed to the disease burden 
Table 2: Comparison of quality of life of respondents in the two health facilities

\begin{tabular}{|c|c|c|c|c|c|c|c|c|c|}
\hline \multirow[t]{2}{*}{ Scale (number of items in scale) } & \multirow[t]{2}{*}{$\mathbf{N}$} & \multicolumn{3}{|c|}{ Central Hospitsal, Warri } & \multirow[t]{2}{*}{$\mathbf{N}$} & \multicolumn{3}{|c|}{ DELSUTH Oghara } & \multirow[b]{2}{*}{$\begin{array}{c}p- \\
\text { value }\end{array}$} \\
\hline & & Mean & SD & Median & & Mean & SD & Median & \\
\hline Symptom/problem list (12) & 102 & 81.39 & 9.08 & 83.33 & 80 & 82.71 & 8.97 & 85.42 & 0.08 \\
\hline Effects of kidney disease (8) & 102 & 68.41 & 15.47 & 78.13 & 80 & 68.52 & 17.75 & 78.13 & 0.96 \\
\hline Burden of kidney disease (4) & 102 & 25.06 & 13.32 & 25.00 & 80 & 27.27 & 14.66 & 25.00 & 0.28 \\
\hline Work status (2) & 102 & 2.94 & 15.45 & 0.00 & 80 & 5.63 & 21.04 & 0.00 & 035 \\
\hline Cognitive function (3) & 102 & 61.63 & 7.11 & 60.00 & 80 & 61.67 & 7.61 & 60.00 & 0.97 \\
\hline Quality of social interaction (3) & 102 & 60.13 & 12.52 & 53.33 & 80 & 59.58 & 11.68 & 53.33 & 0.76 \\
\hline Sexual function (2) & 10 & 55.00 & 30.73 & 75.00 & 14 & 53.57 & 30.79 & 75.00 & 0.91 \\
\hline Sleep (4) & 102 & 82.79 & 12.71 & 90.00 & 80 & 81.66 & 12.26 & 90.00 & 054 \\
\hline Social support $(2)$ & 102 & 99.35 & 4.64 & 100.0 & 80 & 98.75 & 6.37 & 100.0 & 0.46 \\
\hline Dialysis staff encouragement (2) & 102 & 96.08 & 13.51 & 100.0 & 80 & 94.69 & 17.20 & 100.0 & 0.53 \\
\hline Overall health (1) & 102 & 67.25 & 8.22 & 70.00 & 80 & 66.88 & 8.21 & 70.00 & 0.76 \\
\hline Patient satisfaction (1) & 102 & 68.79 & 8.67 & 66.67 & 80 & 69.79 & 11.28 & 66.67 & 0.49 \\
\hline Physical functioning 10) & 102 & 26.23 & 16.42 & 25.00 & 80 & 29.19 & 21.12 & 27.50 & 0.28 \\
\hline Role limitations--physical (4) & 102 & 1.96 & 13.93 & 0.00 & 80 & 3.75 & 19.12 & 0.00 & 0.46 \\
\hline Pain (2) & 102 & 62.38 & 12.94 & 67.50 & 80 & 63.69 & 14.81 & 65.00 & 0.51 \\
\hline General health (5) & 102 & 40.54 & 10.15 & 35.00 & 80 & 41.56 & 12.82 & 35.00 & 0.54 \\
\hline Emotional well-being (5) & 102 & 61.33 & 13.57 & 68.00 & 80 & 60.15 & 17.22 & 68.00 & 0.60 \\
\hline Role limitations--emotional (3) & 102 & 2.61 & 14.60 & 0.00 & 80 & 5.00 & 19.92 & 0.00 & 0.35 \\
\hline Social function (2) & 102 & 47.79 & 11.32 & 50.00 & 80 & 48.13 & 13.94 & 50.00 & 0.85 \\
\hline Energy/fatigue (4) & 102 & 30.39 & 12.02 & 35.00 & 80 & 30.19 & 11.84 & 35.00 & 0.91 \\
\hline SF-12 Physical Health Composite & 102 & 31.08 & 4.62 & 30.82 & 80 & 31.75 & 6.01 & 30.82 & 0.39 \\
\hline SF-12 Mental Health Composite & 102 & 37.73 & 3.37 & 38.86 & 80 & 37.69 & 4.09 & 38.86 & 0.94 \\
\hline
\end{tabular}

Table 3: Relationship between demographic characteristics and PCS

\begin{tabular}{|c|c|c|c|c|}
\hline \multirow[t]{2}{*}{ Variable } & & \multicolumn{2}{|c|}{ SF-12 Physical Component } & \multirow[t]{2}{*}{$P$-value } \\
\hline & & Frequency & Mean \pm SD & \\
\hline \multirow{5}{*}{$\begin{array}{l}\text { Sex } \\
\text { Marital } \\
\text { Status }\end{array}$} & Male & 85 & $31.78 \pm 4.99$ & 0.33 \\
\hline & Female & 97 & $31.02 \pm 5.51$ & \\
\hline & Single & 30 & $31.48 \pm 5.69$ & 0.94 \\
\hline & Married & 150 & $31.41 \pm 5.21$ & \\
\hline & Divorced & 2 & $27.45 \pm 3.96$ & \\
\hline \multirow{8}{*}{ Occupation } & Student & 16 & $32.41 \pm 7.49$ & $>0.05$ \\
\hline & Tailoring & 8 & $30.47 \pm 1.33$ & \\
\hline & Civil Servant & 41 & $31.51 \pm 6.29$ & \\
\hline & Trading (Business) & 69 & $30.87 \pm 4.50$ & \\
\hline & Farming & 2 & $31.29 \pm 5.38$ & \\
\hline & Contractor & 3 & $31.09 \pm 1.75$ & \\
\hline & Plumbing & 2 & $33.57 \pm 0.86$ & \\
\hline & Pensioner & 41 & $31.77 \pm 5.31$ & \\
\hline
\end{tabular}

Table 4: Relationship between demographic characteristics and MCS

\begin{tabular}{|c|c|c|c|c|}
\hline \multirow[t]{2}{*}{ Variable } & & \multicolumn{2}{|c|}{ SF-12 Mental Component } & \multirow[t]{2}{*}{$P$-value } \\
\hline & & Frequency & Mean \pm SD & \\
\hline \multirow{2}{*}{ Sex } & Male & 85 & $37.59 \pm 3.95$ & $>0.05$ \\
\hline & Female & 97 & $37.82 \pm 3.47$ & \\
\hline \multirow{6}{*}{$\begin{array}{l}\text { Marital } \\
\text { Status }\end{array}$} & Single & 30 & $37.64 \pm 3.69$ & $>0.05$ \\
\hline & Married & 150 & $37.75 \pm 3.72$ & \\
\hline & Divorced & 2 & $36.22 \pm 2.61$ & \\
\hline & Student & 16 & $37.41 \pm 4.60$ & $>0.05$ \\
\hline & Tailoring & 8 & $38.27 \pm 2.25$ & \\
\hline & Civil Servant & 41 & $38.03 \pm 3.31$ & \\
\hline \multirow{5}{*}{ Occupation } & Trading (Business) & 69 & $38.13 \pm 3.22$ & \\
\hline & Farming & 2 & $32.45 \pm 1.65$ & \\
\hline & Contractor & 3 & $37.25 \pm 1.73$ & \\
\hline & Plumbing & 2 & $40.52 \pm 4.31$ & \\
\hline & Pensioner & 41 & $36.84 \pm 4.55$ & \\
\hline
\end{tabular}


Table 5: Relationship between biochemical parameters and QoL of patients in the two health facilities

\begin{tabular}{llcc}
\hline Variable & Pearson correlation & $\begin{array}{c}\text { SF-12 Physical } \\
\text { Component }\end{array}$ & $\begin{array}{c}\text { SF-12 Mental } \\
\text { Component }\end{array}$ \\
\hline Urea $(10-50) \mathrm{mg} / \mathrm{dl}$ & Sig. (2-tailed) & -.137 & -.083 \\
& $\mathrm{~N}$ & .065 & .266 \\
& Pearson correlation & 182 & 182 \\
Creatinine $(0.4-1.1)$ & Sig. (2-tailed) & $-.166^{*}$ & -.086 \\
$\mathrm{mg} / \mathrm{dl}$ & $\mathrm{N}$ & .025 & .248 \\
& Pearson correlation & 182 & 182 \\
$\mathrm{Na}(137-147) \mathrm{mmol} / \mathrm{l}$ & Sig. (2-tailed) & -.059 & -.081 \\
& $\mathrm{~N}$ & .429 & .279 \\
& Pearson correlation & 182 & 182 \\
$\mathrm{~K}(3.8-5.1) \mathrm{mmol} / \mathrm{l}$ & Sig. (2-tailed) & $-.202^{* *}$ & .009 \\
& $\mathrm{~N}$ & .006 & .903 \\
& & 182 & 182 \\
\hline
\end{tabular}

*Values in the first column indicate the normal range of $\mathrm{K}, \mathrm{Na}$, urea and creatinine

on the patients. This is consistent with the findings of a study in Brazil which reported a low mean PCS and MCS scores among CKD patients when compared to the general population [16].

For physical composite, role limitation-physical had the lowest mean score and pain had the highest mean score, which is an indication that the patients did not feel much pain. This agrees with a study done in Malaysia where physical composite role limitation had the lowest mean score [17].

For the mental health composite, emotional wellbeing had the highest mean score. This finding corroborates the result of a previous study by a group of researchers who reported emotional well-being as having the highest mean score in the mental health composite, while role limitationemotion had the lowest mean score [17]. This result is an indication that kidney disease dramatically affects patient's performance; hence patients are very much limited in carrying out different physical and emotional roles resulting in a decline in patients QoL.

The mental health composite had a higher mean score when compared to the physical health composite score indicating that renal impairment has more effect on the physical health composite of QoL. This might be because of the ability of the patients to adapt to their health challenge over time psychologically. This agrees with the findings of other similar studies which reported mental health composite as having a higher mean score than the physical health composite [17-19]. The relationship between marital status, occupation, and sex with the quality of life of chronic kidney disease patients was not significant. This finding, however, is inconsistent with that reported by Cruz et al, which stated that there was a significant relationship between these factors and quality of life [16]. Interestingly, sex had no relationship with the quality of life of CKD patients. This disagrees with the report of other studies which reported female gender as a strong predictor of low mean scores of quality of life [16,20-22].

Other researchers have reported a positive correlation between creatinine and physical health composite [23-25], however, in their studies, the increase in creatinine was not thought to be a result of inadequate dialysis but rather due to somatic protein concentration (muscle mass). This implies that in these patients the high creatinine levels was because of high muscle activity suggestive of physical activity. In this study, there was a negative correlation between physical health composite and creatinine as well as potassium showing that as the levels of creatinine and potassium increased, there was a resultant decrease in the QoL of chronic kidney disease patients. This is plausible since increasing creatinine and potassium levels indicate a decline in kidney function, which directly affect the physical well-being of the patients. There was, however, no correlation between biochemical parameters and the mental health composite. 
There was no significant difference between the QoL of patients receiving treatment in both centers. This might be because the patients in both centers have similar medical and environmental conditions which have the same effect on their QoL.

\section{Limitations of the study}

Chronic kidney disease patients were not readily available and this resulted in the small sample size which could have affected the outcome of the study. This study should be replicated in other regions for a more robust study outcome.

\section{CONCLUSION}

The QoL of patients with chronic kidney disease with regard to physical and mental health component scores in the two surveyed settings was low. None of the socio-demographic characteristics had a significant relationship with the QoL of the respondents in both health centres. There was a negative association between the physical health component score and creatinine and potassium. The QoL of patients with CKD in the surveyed population was low. This in future should be taken into account.

\section{DECLARATIONS}

\section{Acknowledgement}

The authors wish to acknowledge the staff and management of Central Hospital, Warri and Delta State University Teaching Hospital, Oghara for their support during the period of the study.

\section{Conflict of interest}

No conflict of interest is associated with this work.

\section{Contribution of authors}

We declare that this work was undertaken by the authors named in this article. All the authors participated in the study and we have collectively agreed to submit this article to your journal for consideration. Ogheneovo Aghoja and Valentine Odili conceived and designed the study. Data collection was done by Omasan Ajagbe. The data was analyzed by Valentine Odili. Ogheneovo Aghoja and Rita Akonoghrere prepared the manuscript. Valentine Odili reviewed the manuscript and all the authors read and approved the final manuscript.

\section{Open Access}

This is an Open Access article that uses a funding model which does not charge readers or their institutions for access and distributed under the terms of the Creative Commons Attribution License (http://creativecommons.org/licenses/by/ 4.0) and the Budapest Open Access Initiative (http://www.budapestopenaccessinitiative.org/rea d), which permit unrestricted use, distribution, and reproduction in any medium, provided the original work is properly credited.

\section{REFERENCES}

1. Levey AS, Coresh J, Balk E, Kausz AT, Levin A, Steffes MW, Hogg RJ, Perrone RD, Lau J, Eknoyan G. National Kidney Foundation. National Kidney Foundation practice guidelines for chronic kidney disease: evaluation, classification, and stratification. Ann Intern Med 2003; 139(2): 137-147

2. St Peter WL, Khan SS, Ebben JP, Pereira BJ, Collins AJ. Chronic kidney disease: the distribution of health care dollars. Kidney Int 2004; 66: 313-321

3. Remuzzi G, Ruggenenti $P$, Perico N. Chronic renal diseases: renoprotective benefits of renin-angiotensin system inhibition. Ann Intern Med 2002; 136: 604-615

4. Manian FA, Stone WJ, Alford RH. Adverse antibiotic effects associated with renal insufficiency. Rev Infect Dis 1990; 12: 236-249

5. Sandler DP, Burr FR, Weinberg CR. Nonsteroidal antiinflammatory drugs and the risk for chronic renal disease. Ann Intern Med 1991; 115: 165-172

6. Turnheim K. Drug therapy in the elderly. Exp Gerontol 2004; 39: 1731-1738

7. Perlman RL, Finkelstein FO, Liu L, Roys E, Kiser M, Eisele G, Burrows-Hudson S, Messana JM, Levin N, Rajagopalan S, et al. Quality of life in chronic kidney disease (CKD): a cross-sectional analysis in the Renal Research Institute-CKD study. Am J Dis 2005; 45(4): 658-666

8. Kalender B, Ozdemir AC, Dervisoglu E, Ozdemir O. Quality of life in chronic kidney disease: effects of treatment modality, depression, malnutrition and inflammation. Int J Clin Pract 2007; 61(4): 569-576

9. Harris LE, Luft CF, Rudy DW, Tierney WM. Clinical Correlates of Functional Status in Patients with Chronic Renal Insufficiency. Am J Kid Dis 1993; 21: 161-166

10. Sesso R, Yoshihiro MM. Time of diagnosis of chronic renal failure and assessment of quality of life in hemodialysis patients. Nephrol Dial Transplant 1997; 12(10): 2111-2116

11. Kimmel PL, Cohen SD, Weisbond SD. Quality of life of patients with end-stage renal disease treated with dialysis: Survival is not enough $\mathrm{J}$ Nephrol 2008; 21 Suppl 13: S54-S58, [Pubmed: 18446733]

12. Leaf $D E$, Goldfarb DS. Interpretation and review of health-related quality of life data in CKD patients

Trop J Pharm Res, August 2020; 19(8): 1764 
receiving treatment for anemia. Kidney Int 2009; 75: 1524, [pubmed: 18813284]

13. Abraham S, Venu A, Ramachandran A, Chandran PM, Raman S. Assessment of quality of life in patients on hemodialysis and the impact of counselling. Saudi $J$ Kidney Transpl 2012; 23: 953-7 [pubmed: 22982906]

14. St Peter WL, Schoolwerth AC, McGowan T, McClellan WM. Chronic kidney disease: issues and establishing programs and clinics for improved patient outcomes. Am J Kidney Dis 2003; 41: 903-924

15. World Medical Association. "Declaration of Helsinki: Ethical principles for medical research involving human subjects. J Am Med Assoc 2013; 310 (20): 2191-2194

16. Cruz MC, Andrade $C$, Urrutia $M$, Draibe $S$, NgueiraMartins LA, de Castro Cintra Sesso R. Quality of life in patients with chronic kidney disease. Clinics 2011; 66(6): 991-995

17. Yusop NB, Mun CY, Shariff $Z M$, Huant CB. Factors Associated with Quality of Life among Hemodialysis Patients in Malaysia. PLOS ONE 2013; 8(12): 1-11

18. Bohlke $M$, Leite $D$, Scaglioni S, Kitamura C, Andrade $M$, Von-Gysel M. Predictors of quality of life among patients on dialysis in Southern Brazil. Sao Paulo Med J. 2008; 126(5): 252-256

19. Spiegel BM, Melmed G, Robbins S, Esrailian E. Biomarkers and health-related quality of life in end-stage renal disease: a systematic review. Clin J Am Soc Nephrol. 2008; 3: 1759-68, DOI: 102215/CJN.00820208.

20. Rocco MV, Gassmann JJ, Wang SR, Kaplan RM. Crosssectional study of quality of life and symptoms in chronic renal disease patients: The Modification of Diet in Renal Disease study. Am J Kidney Disease. 1997; 29: 888896. [pubmed:9186075]

21. Chow FW, Briganti FM, Kerr PG, Chadbam SJ, Zinmet $P Z$, Atkins RC. Health-related quality of life in Australian adults with renal insufficiency: $A$ population-based study. Am J Kidney Dis 2003; 41: 596-604 [pubmed: 16731290]

22. Panniagua $R$, Amato $D$, Vonesh E, Guo A, Mujais S. Health-related quality of life predicts outcome but is not affected by peritoneal clearance: The ADMEX trial. Kidney Int. 2005; 67: 1093-1104. [pubmed:15698450]

23. Allen KL, Miskulin D, Yan G, Dwyer JT, Frydrych A, Leung MS, Poole RD. Hemodialysis (HEMO) study group: Association of nutritional markers with physical and mental health status in prevalent hemodialysis patients from the HEMO study. J Ren Nutr 2002; 12: 160-169 doi 10.1053/jren2012 33512 pubmed: 12105813

24. Kalantar-Zadeh $K$, Kuwae N, Wu DY, Shantouf RS, Fouque D, Anker SD, Block G, Kopple JD. Association of body fat and its changes over time with quality of life and prospective mortality in hemodialysis patients. Am J Clin Nutr. 2006; 83(2): 202-210

25. Borzou SR, Gholyaf M, Zandha M, Amina R, Goodarzi $M T$, Torkaman B. The effect of increasing blood flow rate on dialysis adequacy in haemodialysis patients. Saudi J Kidney Transpl 2009; 20: 639-642 [pubmed: 19587505]. 